\title{
Examining the Effectiveness of a Semi-Self-Paced Flipped Learning Format in a College General Chemistry Sequence
}

\author{
Lisa Hibbard, ${ }^{*}{ }^{\dagger}$ Shannon Sung, ${ }^{\dagger}$ and Breché Wells ${ }^{\dagger}$ \\ ${ }^{\dagger}$ Department of Chemistry and Biochemistry and ${ }^{\ddagger}$ Education Studies Program, Spelman College, Atlanta, Georgia 30314, United \\ States
}

\section{Supporting Information}

\begin{abstract}
Flipped learning has come to the forefront in education. It maximizes learning by moving content delivery online, where learning can be self-paced, allowing for class time to focus on student-centered active learning. This five-year cross-sectional study assessed student performance in a college general chemistry for majors sequence taught by a single instructor, comparing the flipped learning format to a more traditional lecture format. Students' conceptual knowledge was captured through the use of American Chemical Society (ACS) standardized exam scores and analyzed using one-way ANCOVA. Student motivation and learning perceptions were assessed using the Chemistry Motivation Questionnaire (CMQ-II) and an in-house Blended (Flipped) Learning Survey. Statistical analysis indicated that students instructed through the flipped learning platform performed better than those taught using traditional pedagogy. Student perceptions regarding flipped learning were mostly positive and reflected motivation to succeed. Educational implications and significance of this work are discussed.
\end{abstract}

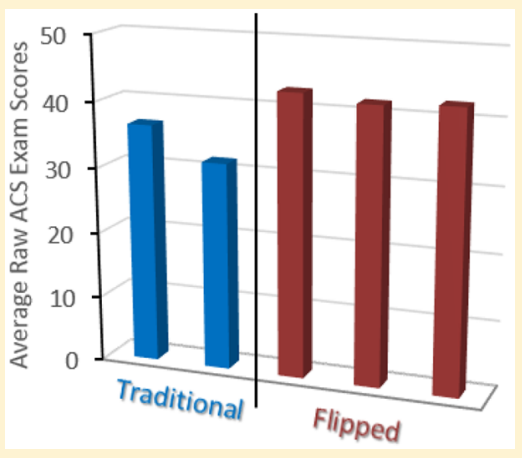

KEYWORDS: First Year Undergraduate/General, Chemical Education Research, Internet/Web-Based Learning, Collaborative/Cooperative Learning, Testing/Assessment

FEATURE: Chemical Education Research

\section{INTRODUCTION}

Many colleges and universities have begun offering blended courses, which combine best practices from face-to-face and online learning. One category of blended instruction that has come to the forefront in education is the flipped or inverted classroom format, which maximizes learning by moving content delivery online, allowing for classroom sessions to focus on student-centered activities. While this concept of shifting the learning of course material to outside of class so that more meaningful student engagement can take place in class has been around since the 1990s, ${ }^{1,2}$ the advent of new and improved technology has allowed the flipped classroom to become more widely implemented. ${ }^{3}$ Two of the earliest developers of the technology-enhanced flipped instructional method are Jonathan Bergmann and Aaron Sams, who recorded online lectures for their high school chemistry course and published their observations and recommendations in their book Flip Your Classroom: Reach Every Student in Every Class Every Day. ${ }^{4}$ Since then, there have been a growing number of blogs, Web sites [e.g., Flipped Learning Network, Edutopia, Jon Bergmann's Web site, etc.], literature reviews, and publications that offer advice on best practices in flipped learning. ${ }^{5-8}$ When reviewing the literature and online postings, it becomes clear that these courses vary widely based on the setting $(\mathrm{K}-12$ or college level), course topic, learning objectives, available technology, and extent to which the students and instructor are required to meet in a face-to-face setting.

Educators agree that, when course content, student-centered classroom sessions, and assessment tools are integrated thoughtfully, the flipped learning model offers a number of benefits. Mounting evidence has shown that use of this strategy can lead to higher levels of student performance. ${ }^{9-13}$ Other more qualitative benefits reported by instructors include more efficient use of class time, ${ }^{14}$ increased student engagement, ${ }^{15,16}$ increased student-teacher and peer interactions, ${ }^{19}$ and students taking responsibility for their own learning. ${ }^{18,19}$

The idea of using student-centered active learning techniques is not a new one in the sciences. ${ }^{20-22}$ Attention has been given to instructional strategies such as inquiry-based learning (IBL, including Process Oriented Guided Inquiry Learning, POGIL), ${ }^{23,24}$ problem-based learning (PBL), ${ }^{25}$ case-based learning $(\mathrm{CBL}),{ }^{26}$ team-based learning (TBL), ${ }^{27}$ and peer-led team learning (PLTL). ${ }^{28}$ These strategies focus on deeper learning activities (based on the revised Bloom's Taxonomy) ${ }^{29}$ recognizing the various ways in which students learn and retain knowledge. ${ }^{30}$ But it can be argued that, with new technological advances and the widespread use of course learning management systems (LMSs) on campuses, the integration of online content delivery with in-class student-centered activities improves the teaching and learning dynamic by promoting increased student-teacher and peer interactions in the classroom.

Published: November 5, 2015 
Technology-enhanced content and assessment platforms allow students the ability to work at their own pace to a certain extent (hence the designation "semi-self-paced"). The sense of independence and ownership over learning that the student gains reflects some of the best aspects of studentregulated learning. ${ }^{31}$ Formative assessments can be handled through online learning platforms, through LMSs, and using inclass technology. ${ }^{32,33}$ Online content with embedded assessments gives students immediate feedback so that they can identify points of confusion before class; clickers or online polling sites assess student preparedness and knowledge misconceptions in class; ${ }^{34}$ and online homework has been shown to improve student performance. ${ }^{35}$ Various learning styles are, thus, supported by scaffolding the online environment with a face-to-face setting that reinforces learning and stimulates inquiry. ${ }^{4}$

While most LMSs support online testing, many instructors still use in-class tests to avoid issues with test security. Additionally, many schools use the standardized ACS exam as a summative assessment of student learning over a term or year. Exam outcomes provide information regarding specific knowledge gains ${ }^{36}$ and can also be used to compare student performance after new instructional methods are implemented, as is seen in recent research on the use of the flipped classroom format in the general chemistry course. ${ }^{37}$

\section{PURPOSE AND RESEARCH QUESTIONS}

Quantitative information regarding student learning gains in the flipped learning environment is limited. The purpose of this research has been to assess the impact of a flipped learning instructional format on student performance and knowledge retention in a college-level General Chemistry for Majors course sequence.

Research questions included

1. Does the use of a flipped learning format impact student performance as compared to the more traditional instructional format?

2. Does the use of a flipped learning format impact student motivation and attitude toward learning?

\section{METHODS}

\section{Setting}

This study was conducted at a 4-year Historically Black College and University (HBCU) for women in the Southeast. Approximately $7 \%$ of incoming First Year students select Chemistry or Biochemistry as a major. The Department of Chemistry and Biochemistry has traditionally offered three separate course sections each of General Chemistry I ( $\mathrm{CHE}$ 111 ) in the fall and General Chemistry II (CHE 112) in the spring, with average fall enrollments of approximately 40 students per section. Classes traditionally meet for four $50 \mathrm{~min}$ sessions each week. This course sequence is required of all department majors, sophomore Biology majors, and students in the prehealth professional track.

\section{Course Format}

In 2009, one of the three general chemistry sections in both CHE 111 and 112 became a dedicated section required for all First Year majors. The General Chemistry for Majors sequence is not exclusive; sophomores comprise anywhere from 5 to $30 \%$ of the class. The majors' courses cover the same material and use the same textbook as the other two sections, which are taught by different instructors using a traditional lecture format. Students in all three sections take a common semester ACS final exam.

The majors' courses were initially revised to incorporate POGIL and team-based learning strategies used in conjunction with instructor-developed PowerPoint slides, made available to students through the open source online learning platform, Moodle (moodle.org), which the college utilizes as the campus Learning Management System (LMS). Class time involved the instructor lecturing from these slides and then students working in teams during problem-solving or POGIL sessions. Clicker quizzes were utilized weekly to assess student comprehension of concepts. Students were also required to use an online homework system (most recently McGraw-Hill's Connect.)

The majors' courses also differed from the traditional lecture sections in how students were tested. While other instructors administered 3-4 multiple-chapter tests each term, the majors' section offered "gated" chapter tests (i.e., gates.) In this system, students took a chapter gate multiple times (questions vary for each iteration) in order to pass before moving to the next chapter gate. Students were allowed four attempts to pass with a minimum score of $85 \%$. Gates were offered 4-5 times per week over a 1.5-2-week time frame. Students not passing a gate by the time it closed were scored 10 points per attempt. The intent of this iterative testing system was to push students to master difficult concepts shortly after learning the material.

The course sequence was revised again in 2012-13 using a semi-self-paced flipped learning format. Preclass, in-class, and postclass activities were developed and outlined in chapter schedules provided to the students at the beginning of the term. For preclass activities, students were assigned textbook readings, which tied in with instructor-narrated online lecture presentations or "LOLs" (lectures online) posted on the LMS. Imbedded within LOLs were problems to be covered during the next class period during in-class puzzles or problem-solving sessions (IPOPS). Students were expected to review and take notes on LOLs and assigned textbook readings before class and to attempt associated problems found in the LOLs. Students were required to keep their work in a notebook that the instructor briefly checked at each classroom session.

When the flipped learning format was first implemented in 2012-13, the class met face-to-face 4 days a week. The next year, the class was changed to meet 3 days per week based on the fact that students were spending larger amounts of time preparing for class. For in-class sessions, students worked in miniteams of two, which often paired up in megateams. While teams reviewed IPOPS problems or worked through POGIL worksheets, the instructor walked around the classroom answering questions presented by teams or individuals. After the instructor had determined that the majority of students were prepared, teams were randomly called upon to respond to questions in order to receive participation points.

Several in-class activities utilized technology to teach process skills and critical thinking. Miniteams checked out iPads, provided by the department, to use apps involving simulations and molecular modeling or present problem responses via whiteboard screen sharing. Most class periods either began or ended with clicker quizzes that assessed class preparation and/ or concept comprehension.

Postclass activities consisted of using a digital teaching/ learning environment and adaptive learning system. The online adaptive learning component, LearnSmart, which is part of McGraw-Hill's Connect system, allowed students to assess their 
understanding of a given topic in order to identify knowledge gaps. The online homework system (most recently, McGrawHill's Connect) allowed randomization of problems and multiple attempts before submittal. Students also periodically contributed to projects either individually or in teams, including wikis and case study analysis.

Final course grades were determined based on the broad categories of Preparation (23.3\%), which included notebook work, quizzes, and Connect/LearnSmart assignment grades; Participation (23.3\%), which included team assessment, in-class participation, projects, and an electronic portfolio; Gated Test scores (30\%); and the ACS final exam score (23.3\%).

\section{Research Methods and Assessment}

The research data reported spans five academic years (AY) where the General Chemistry I (CHE 111) and II (CHE 112) for Majors courses were taught by the same instructor. Table 1

Table 1. Pedagogical Methods and Assessments Used in General Chemistry I and II for Majors

\begin{tabular}{lccccc}
$\begin{array}{c}\text { Academic Year } \\
\text { (AY) Method }\end{array}$ & 2009-10 & $2010-11$ & $2012-13$ & $2013-14$ & $2014-15$ \\
Flipped format & & & $\mathrm{X}$ & $\mathrm{X}$ & $\mathrm{X}$ \\
Periods/week & 4 & 4 & 4 & 3 & 3 \\
POGIL worksheets & $\mathrm{X}$ & $\mathrm{X}$ & $\mathrm{X}$ & $\mathrm{X}$ & $\mathrm{X}$ \\
Unnarrated & $\mathrm{X}$ & $\mathrm{X}$ & & & \\
$\quad \begin{array}{l}\text { PowerPoint } \\
\text { slides }\end{array}$ & & & & & \\
Narrated & & & $\mathrm{X}$ & $\mathrm{X}$ & $\mathrm{X}$ \\
$\quad \begin{array}{l}\text { PowerPoint } \\
\text { slides }\end{array}$ & & & & & \\
Notebook & & & $\mathrm{X}$ & $\mathrm{X}$ & $\mathrm{X}$ \\
$\begin{array}{l}\text { Online homework } \\
\text { Adaptive learning }\end{array}$ & $\mathrm{X}$ & $\mathrm{X}$ & $\mathrm{X}$ & $\mathrm{X}$ & $\mathrm{X}$ \\
$\quad \mathrm{system}$ & & & $\mathrm{X}$ & $\mathrm{X}$ \\
Gated testing & $\mathrm{X}$ & $\mathrm{X}$ & $\mathrm{X}$ & $\mathrm{X}$ & $\mathrm{X}$ \\
$\begin{array}{l}\text { ACS Final Exams } \\
\text { CMQ-II } \\
\text { questionnaire }\end{array}$ & $\mathrm{X}$ & $\mathrm{X}$ & $\mathrm{X}$ & $\mathrm{X}$ & $\mathrm{X}$ \\
In-house survey & & & & $\mathrm{X}$ & $\mathrm{X}$ \\
\hline
\end{tabular}

indicates the similarities and differences between the more traditional format and the flipped learning format used each year. Each year students had access to free tutoring services on campus.

Class composition varied each semester in terms of number of enrolled students, major identification, and student classification. All enrolled students were women of traditional college age and identified as African-American women, with a small number $(2-5)$ of international students from Africa. First Year students selecting a major in Chemistry or Biochemistry were required to enroll in the CHE 111 Majors course. Sophomore nonmajors requiring chemistry as a prerequisite were allowed to enroll with instructor permission. At the beginning of each term, students willing to participate in the study signed an approved IRB form and filled out information sheets where they listed their major, classification, course enrollment, and previous math course. Additional information was obtained regarding SAT/ACT math scores (some students took both standardized tests; international students were not required to take either test) and high school AP Chemistry exam scores. Because student mathematics competency has been reported to be an important indicator for success in general chemistry, the ACT math scores were converted in concordance to the SAT math scores. ${ }^{38}$ Table 2 summarizes this student demographic information for each section in the CHE 111/112 for Majors sequence for five academic years (AY).

In order to determine the correlation between student performance and motivation for studying chemistry, the Chemistry Motivation Questionnaire II (CMQ-II) (in which "chemistry" replaced the word "science" in the original Science Motivation Questionnaire II) ${ }^{39}$ was administered to students enrolled in the majors' courses at the beginning of the spring term of 2014 (CHE 112) and at the beginning of the fall term of 2014 (CHE 111). The CMQ-II includes 25 questions that measure five factors: intrinsic motivation, self-determination, self-efficacy, career motivation, and grade motivation. Student responses are on a rating scale range of frequency: "never $(0)$ ", "rarely (1)", "sometimes (2)", "usually (3)", or "always (4)." The reliability for each factor and the overall instrument was analyzed using Cronbach's alpha. Student response averages from the CMQ-II instrument were then compared to the final course letter grades earned. [Refer to http://www.coe.uga.edu/ smq/ for the CMQ-II Web site and articles.]

An in-house 50-question survey was developed that surveyed student perceptions and feelings about blended (flipped) learning activities. This anonymous survey was administered in Spring 2015 to students currently enrolled in the CHE 112 majors course and in chemistry courses enrolling sophomores, juniors, and seniors who had taken the CHE 111/112 majors sequence in prior years. The survey was divided into four sections: content delivery, classroom sessions, assessments, and learning motivation/prior experience. Student responses were based on a Likert-type scale: $5=$ strongly agree, $4=$ agree, $3=$ neutral, 2 = disagree, and $1=$ strongly disagree. [Refer to Supporting Information for the survey and results.]

American Chemical Society (ACS) standardized exams were administered to the combined three course sections each term. The ACS 2002 General Chemistry First Term Gray Form was used for all three CHE 111 sections each fall semester, and the ACS 2003 Full Term Standardized Test Gray Form was used as the comprehensive full-year final exam for the three CHE 112 sections each spring. Each exam is composed of 70 multiple

Table 2. Student Demographics in General Chemistry I $(\mathrm{F}=$ Fall $)$ and II $(S=$ Spring $)$ for Majors

\begin{tabular}{|c|c|c|c|c|c|c|c|c|c|c|}
\hline & \multicolumn{2}{|c|}{$2009-10$} & \multicolumn{2}{|c|}{$2010-11$} & \multicolumn{2}{|c|}{$2012-13$} & \multicolumn{2}{|c|}{$2013-14$} & \multicolumn{2}{|c|}{$2014-15$} \\
\hline & $\mathrm{F}$ & $S$ & $\mathrm{~F}$ & $S$ & $\mathrm{~F}$ & S & $\mathrm{F}$ & $S$ & $\mathrm{~F}$ & $S$ \\
\hline Majors enrolled & 43 & 33 & 38 & 23 & 28 & 21 & 37 & 25 & 25 & 20 \\
\hline Nonmajors enrolled & 2 & 7 & 12 & 18 & 3 & 1 & 4 & 2 & 12 & 15 \\
\hline Av Math SAT $(n)$ & \multicolumn{2}{|c|}{$518.5(40)$} & \multicolumn{2}{|c|}{$506.4(45)$} & \multicolumn{2}{|c|}{$554.2(24)$} & \multicolumn{2}{|c|}{$550.7(28)$} & \multicolumn{2}{|c|}{$570.9(32)$} \\
\hline Av Math ACT $(n)$ & \multicolumn{2}{|c|}{$22.5(34)$} & \multicolumn{2}{|c|}{$22.0(46)$} & \multicolumn{2}{|c|}{$23.5(16)$} & \multicolumn{2}{|c|}{$24.7(24)$} & \multicolumn{2}{|c|}{$24.2(20)$} \\
\hline Av AP score $(n)$ & \multicolumn{2}{|c|}{$3(1)$} & \multicolumn{2}{|c|}{$1(2)$} & \multicolumn{2}{|c|}{$2(6)$} & \multicolumn{2}{|c|}{$1.4(5)$} & \multicolumn{2}{|c|}{$1.5(2)$} \\
\hline Av Math SAT/ACT concordance score, spring term only $(n)$ & \multicolumn{2}{|c|}{$536.5(37)$} & \multicolumn{2}{|c|}{$517.8(40)$} & \multicolumn{2}{|c|}{$566.2(21)$} & \multicolumn{2}{|c|}{$552.0(25)$} & \multicolumn{2}{|c|}{$580.3(30)$} \\
\hline
\end{tabular}


choice questions. The ACS 2003 exam was used to measure not only understanding of second term concepts but also retention of knowledge as approximately half of the questions come from concepts covered during the first term.

Students' raw scores on the cumulative year ACS standardized exam from five spring term cohorts were documented with the descriptive statistics. An ANCOVA (analysis of covariance) analysis was performed to determine whether there is significant difference between traditional and flipped learning formats controlling for the SAT/ACT math concordance scores. The one-way ANCOVA was analyzed with SPSS statistics software version $20 .^{40}$ The independent variable was the different classes using either traditional or flipped learning format in the spring terms of each academic year (refer to Table 1.) The dependent variable was the ACS standardized test scores out of a possible 70 , and the covariate was the SAT/ACT math concordance score.

\section{RESULTS}

The ACS standardized exams were graded on a raw score scale with 70 as the maximum possible score. Figure 1 illustrates the results of the ACS exams for the General Chemistry I and II for Majors courses both fall and spring terms over the 5-year period indicated.

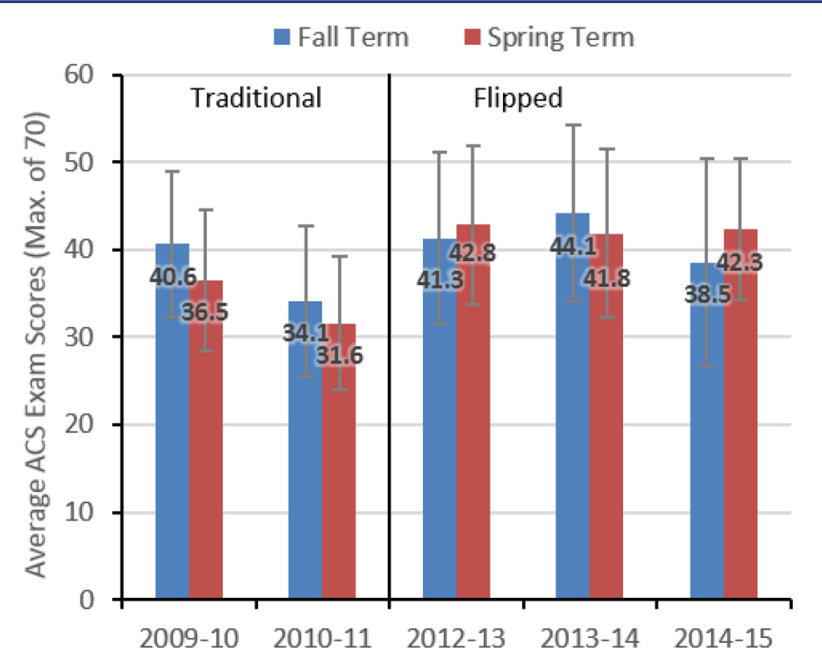

Figure 1. ACS General Chemistry Exam raw score averages (out of 70) for 5 academic years. AY 2009-10 and 2010-11 were taught using a traditional lecture format; AY2012-13, 2013-14, and 201415 courses were taught using the flipped learning format.

The one-way ANCOVA was found to have a statistically significant main effect, $F(4,147)=9.212, p=0.000$. The strength of relationship between the five-year ACS test data for traditional vs flipped learning instruction was small to moderate, as assessed by its effect size (partial $\eta^{2}=0.200$ ), holding constant the SAT/ACT math concordance scores. The result indicates that there was significant difference between different pedagogical strategies; however, only $20 \%$ of the total variance in ACS test scores was accounted for by different pedagogies controlling for the effect of SAT/ACT math concordance scores. $^{41}$

The Chemistry Motivation Questionnaire II responses for two student cohorts were analyzed based on average response scores to each of the five motivation factors as well as all 25 questions [refer to the CMQ-II Responses found in the Supporting Information]. These average scores were then related to course final grades. Responses obtained from the CHE 111 cohort at the beginning of the Fall 2014 term showed no observable pattern with final course grades, however, a pattern was observed for the cohort that had successfully passed the Fall 2013 CHE 111 course in relation to the final letter grade received in the Spring 2014 course (Figure 2). The

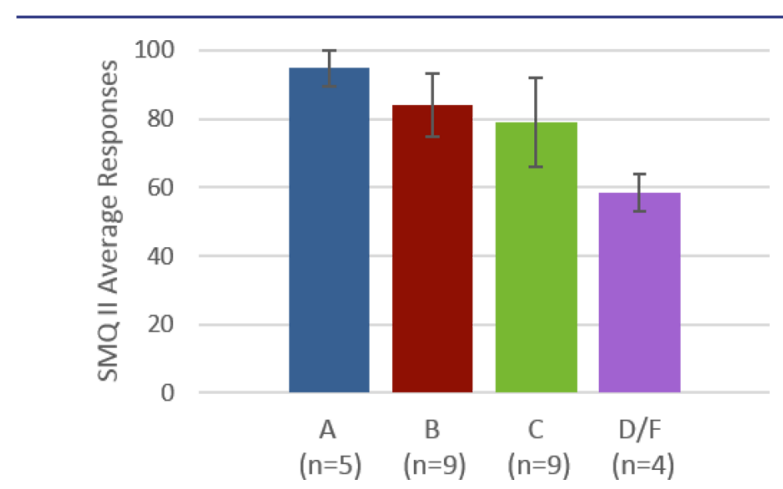

Figure 2. Chemistry Motivation Questionnaire II (CMQ-II) average responses (Spring 2014) in relation to final course grades.

average, $m$, and standard deviation, sd (in parentheses), for the responses to each factor, intrinsic motivation (F1), career motivation (F2), self-determination (F3), self-efficacy (F4), and grade motivation (F5), are as follows: $m_{\mathrm{F} 1}=14.24\left(\mathrm{sd}_{\mathrm{F} 1}=\right.$ 3.46); $m_{\mathrm{F} 2}=16.68\left(\mathrm{sd}_{\mathrm{F} 2}=4.21\right) ; m_{\mathrm{F} 3}=14.93\left(\mathrm{sd}_{\mathrm{F} 3}=3.38\right)$; $m_{\mathrm{F} 4}=15.00\left(\mathrm{sd}_{\mathrm{F} 4}=3.88\right) ; m_{\mathrm{F} 5}=18.10\left(\mathrm{sd}_{\mathrm{F} 5}=1.54\right)$. The low reliability for grade motivation can be attributed to the consistently high responses (e.g, $3 \mathrm{~s}$ or $4 \mathrm{~s}$ ) given by the students, thus yielding little variability in responses and resulting in low interitem covariance. The reliabilities (internal consistencies) of each factor were assessed using Cronbach's alpha. These values for the five factors, F1 through F5, are as follows, with the original developers' reliability values indicated in parentheses: ${ }^{39} \mathrm{~F} 1=0.82(0.89) ; \mathrm{F} 2=0.92(0.92) ; \mathrm{F} 3=0.83$ $(0.88)$; F4 $=0.85$ (0.83); and F5 = $0.13(0.81)$. The Cronbach's alpha for the overall CMQ-II instrument was 0.90 (0.92). All of the Cronbach's alpha values showed very good reliability with the exception of the grade motivation factor.

The General Chemistry anonymous survey was analyzed for negative, neutral, and positive responses to selected questions reflecting the four categories of content delivery, classroom sessions, assessments, and learning motivation. The content delivery questions selected focused on clarity of learning objectives, the use of online narrated PowerPoint presentations, and IPOPS problems. The classroom session questions selected focused on how students prepare for class, POGIL worksheets, team-based learning, minilectures, and clicker quizzes. The assessment questions selected focused on the use of the LearnSmart/Connect system, gated testing, and student perceptions of how this pedagogy impacted final grades. The learning motivation questions selected focused on student learning responsibilities, motivation for working independently, comparison of flipped learning to traditional lecture, social interactions, and the use of the tutoring center. Student respondents $(n=48)$ were classified as First Years, Sophomores, or Juniors who were currently enrolled in the CHE 112 course or had previously completed the CHE 111/ 112 sequence. Figure 3 shows the cumulative responses for the four categories described. Responses by different classifications of students were similar to the exception of classroom sessions and learning motivation. Juniors $(n=8)$ felt more positive 

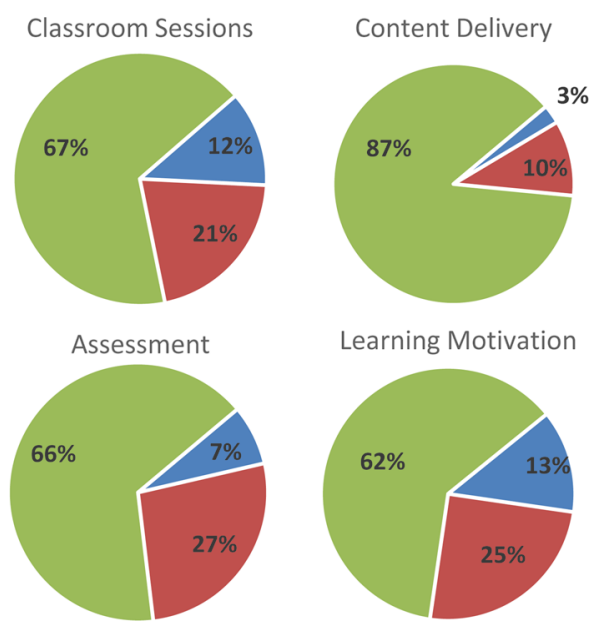

Learning Motivation

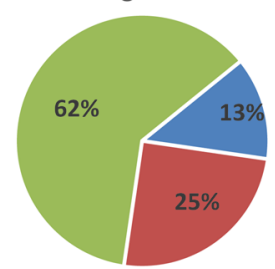

Figure 3. Results from survey pertaining to student perceptions of the flipped learning format.

about the classroom session activities (75\% positive responses) as compared to First Years and Sophomores $(n=40 ; 65 \%$ positive). This difference was also reflected in the learning motivation question responses: Juniors indicated that they were more motivated and learned more easily under the flipped learning format (75\%) as compared to First Years and Sophomores (60\%).

The following survey items received the most positive responses: "Presentations on Moodle met my learning needs", "I believe that a student can earn a higher grade under the blended (flipped) learning system", and "Being responsible for learning course material motivated me to succeed in the courses." The most negative/neutral responses involved the following questions: "I learn better during team-based classroom sessions" and "I liked to work with the tutors in the Chemistry Learning Center."

Survey ratings were supported by several comments given by students over the past few years in the end-of-term student evaluations. The following comments show a sampling of a variety of student perspectives on the flipped learning format and specific activities: "The LOL-IPOPS were really helpful because they thoroughly discussed the concepts at hand. The POGIL worksheets also applied the concepts, confirming whether I grasped each concept"; "The readings online with the LearnSmart definitely help me learn the material because it makes me apply my reading as soon as I learn it"; "[The] instructor makes learning a responsibility. We're very active in our learning and I appreciate that"; "Gates make me learn the material \& set the bar higher for myself instead of learning something once \& forgetting it just so I can make that passing grade"; "I feel as if we are constantly juggling between a million things from worksheets to online hw[homework] to gates to LOL-IPOPS that I sometimes feel like I can't focus \& have to find my way through everything just to get by"; "The 'backwards classroom' is difficult sometimes. It would be nice to be taught and not have to teach myself and do the work."

\section{DISCUSSION}

Overall, it was observed that flipped learning was beneficial in improving student performance as evidenced by a comparison of ACS standardized exam score averages from classes using the semi-self-paced flipped learning format to those taught using a more traditional format (Figure 1). Of particular interest are the cumulative year ACS exam scores from the spring term final exam as they represent knowledge retention from the first term course as well as information that the majority of students have not seen prior to college. Raw score averages over the past three spring terms $(42.8,41.8$, and 42.3 , respectively) exceeded the national average $($ mean $=41.0$; standard deviation $=12.2$ ) for the first time since the exam was first administered at the college in 2005. One-way ANCOVA statistical analysis showed that, overall, the ability measure for flipped learning treatment groups was better than that for the traditional class.

Improved student performance on the cumulative year ACS exam may be due, in part, to students interacting with specific course content over a time span that reinforces knowledge retention and lessens the intrinsic cognitive load inherent to complicated tasks performance. Scaffolding preclass, in-class, and postclass activities allows students to self-pace as they review and revisit content, practice skills, and apply knowledge over time, which has been shown to improve knowledge retention and promote subject mastery. ${ }^{42}$ This is reflected in the mostly positive student perceptions of how well the online learning components helped them prepare for summative assessments and the impact on their final grades (refer to “Assessment" average responses in Figure 3).

One of the most important aspects of using an innovative instructional format is the impact on student motivation. Education research has shown a strong correlation between motivation and achievement, particularly with regard to gender. ${ }^{43}$ The flipped learning format requires students to take ownership of their learning and rewards those who are motivated to learn. The majority ( $81 \%)$ of students in the inhouse anonymous survey indicated that being responsible for their own learning motivated them to succeed in the course. This relationship between motivation and success was reflected in the course grade outcomes. This connection did not occur at the onset, however, as evidenced by the fact that no pattern was observed between CHE 111 student overall motivation responses (CMQ-II) and final course grades that term. For those students who successfully passed CHE 111 and took the CHE 112 course, a pattern was observed between motivation and course performance (Figure 2). This is also reflected in the more detailed analysis of the CMQ-II data, where the item averages for all five motivation factors ranged from 2.99 to 3.62 out of a maximum of 4 , meaning that the students' motivation demonstrated by each factor was high.

Student perceptions play a critical role in their acceptance of this new instructional format. Information obtained from the in-house survey (Figure 3) and student evaluation comments showed that most students were receptive to this pedagogical strategy and believed that they could perform to a higher level. The majority of students ( $87 \%$ ) felt that they learned from the online narrated lectures (LOLs) and the associated practice problems (IPOPS). Classroom sessions (67\%) and assessment techniques (66\%) were also looked upon favorably. In reviewing student evaluation free responses, while most comments were positive, a common criticism was that students would prefer a more traditional lecture as compared to the team-based learning that took place. Anecdotal evidence over the years has shown that many high-performing First Year college students do not feel that they gain much from working in teams. It is, therefore, important to periodically discuss the benefits of working in teams and have students assess their team members' and their own level of participation based on a student-built rubric. Among the various assessment techniques 
used, the gated testing system was rated among the most highly favored. The majority of students liked that the bar was set high in terms of passing and appreciated being given multiple opportunities to correct mistakes. The overall rating score for the assessment category was lowered due to students' thoughts regarding the online adaptive learning system LearnSmart. While most students saw the benefits in using this system, others indicated that it took too much of their time to complete. Student preparation also impacted final grades as observed when assessing student notebooks; those coming to class unprepared did not perform as well. It is clear that those students who mastered time management and organizational skills were able to take full advantage of this pedagogical methodology.

Finally, while this data is compelling, it must be kept in mind that this study is based on a quasi-experimental design as there were no true control classes. Over the time frame of this study the course enrollment, the time the course was offered, the ratio of majors to nonmajors, the number of days the class met, and the student demographics differed. While specific factors such as higher average SAT/ACT math scores or having a higher percentage of First Year majors (who would seem to be more invested in the introductory course in their major) versus sophomore non-Chemistry majors (most of whom are more grade-driven because of being in a prehealth track) in a given class might lead to predictions regarding ACS test outcomes, these factors vary from term to term. Therefore, while one cannot state with certainty that the use of the flipped learning format improves ACS standardized test performance based on the small effect size of this study, the fact that the scores increased significantly as compared to those taught using a traditional lecture format does tend to point to the usefulness of this teaching strategy.

\section{CONCLUSIONS AND FUTURE WORK}

This study has shown that the flipped learning environment incorporates a more active learning environment that improves student performance and enhances self-reported student selfefficacy. These results corroborate some of the more recent findings regarding the use of flipped pedagogical techniques in college-level general chemistry courses. ${ }^{37,44,45}$ While some of the activities and assessment methods described (e.g., gated testing) may only be conveniently utilized in smaller classroom settings, many of these strategies described in this paper can be applied in large classrooms and in a variety of chemistry courses.

One expected long-term impact of using the flipped learning format is to improve attrition rates in the major. An analysis has been performed to determine the numbers of students who changed to a major other than chemistry or biochemistry after the first year. During the three academic years prior to implementing the flipped learning classroom, 33.6\% $(n=36)$ of the First Year students identifying as chemistry or biochemistry majors $(n=107)$ changed major after having taken either or both courses of the CHE $111 / 112$ sequence; this is in comparison to the most recent three-year period where $20.7 \%$ $(n=19)$ of the First Year major cohort $(n=92)$ changed to different majors after taking the general chemistry for majors sequence taught using the flipped learning format. Another anticipated long-term outcome is an increase in student knowledge retention over time. Student cohorts in the pipeline of the majors' sequence are now being followed as they progress through the curriculum. Preassessment tests are being developed for Organic Chemistry and upper level courses, the analysis of which will show whether students retain knowledge over time.

\section{ASSOCIATED CONTENT}

\section{Supporting Information}

The Supporting Information is available on the ACS Publications website at DOI: 10.1021/acs.jchemed.5b00592.

In-house General Chemistry Course Survey (PDF) CMQ-II item responses (PDF)

\section{AUTHOR INFORMATION}

\section{Corresponding Author}

*E-mail: 1hibbard@spelman.edu.

Notes

The authors declare no competing financial interest.

\section{ACKNOWLEDGMENTS}

This research was supported by NSF Targeted Infusion Grant \#1332575 (PI, L. Winfield; co-PI, L. Hibbard) and HHMI Undergraduate Education Program Grant \#52007559. The authors would also like to thank Dr. Shawn Glynn in the Department of Educational Psychology at the University of Georgia for his guidance.

\section{REFERENCES}

(1) King, A. From sage on the stage to guide on the side. College Teaching 1993, 41 (1), 30-35.

(2) Mazur, E. Peer Instruction: A User's Manual Series in Educational Innovation; Prentice Hall: Upper Saddle River, NJ, 1997.

(3) Pacansky-Brock, M. Best Practices for Teaching with Emerging Technologies (Best Practices in Online Teaching and Learning); Routledge: 2012.

(4) Bergmann, J.; Sams, A. Flip Your Classroom: Reach Every Student in Every Class Every Day; ISTE; ASCD: Eugene, OR, Alexandria, VA, 2012.

(5) Aronson, N.; Arfstrom, K.; Tam, K. Flipped Learning in Higher Education; PearsonPD.com. http://www.flippedlearning.org/cms/ lib 07 / VA 01923112 / Centricity/Domain/ $41 /$ HigherEdWhitePaper\%20FINAL.pdf (accessed 22 June 2015).

(6) Hamdan, N.; McKnight, P.; McKnight, K.; Arfstrom, K. A Review of Flipped Learning; June 2013. http://researchnetwork.pearson.com/ wp-content/uploads/LitReview_2014_FlippedLearning_vFinal_JK_ WEB.pdf, (accessed 22 June 2015).

(7) Yarbro, J.; Arfstrom, K.; McKnight, K.; McKnight, P. Extension of A Review of Flipped Learning; June 2014. http://researchnetwork. pearson.com/wp-content/uploads/613_A023_FlippedLearning 2014_June_SinglePage_f.pdf, (accessed 22 June 2015).

(8) Gerstein, J. Flipped Classroom Model: The Full Picture for Higher Education; 2012, https://usergeneratededucation.wordpress.com/ 2012/05/15/flipped-classroom-the-full-picture-for-higher-education/ (accessed 23 June 2015).

(9) Fulton, K. Time for Learning: Top 10 Reasons Why Flipping the Classroom Can. Change Education; Corwin, a SAGE Company: Thousand Oaks, CA, 2014.

(10) Means, B.; Toyama, Y.; Murphy, R.; Bakia, M.; Jones, K. Evaluation of Evidence-Based Practices in Online Learning: A MetaAnalysis and Review of Online Learning Studies; U.S. Department of Education: Washington, DC, 2009.

(11) Street, S. E.; Gilliland, K. O.; McNeil, C.; Royal, K. The flipped classroom improved medical student performance and satisfaction in a pre-clinical physiology course. Med. Sci. Educ. 2015, 25 (1), 35-43.

(12) Smith, D. CoS 2015:10 Reasons Flipped Classrooms Could Change Education; http://www.edtechmagazine.com/k12/article/2015/03/ 
cosn-2015-10-reasons-flipped-classrooms-could-change-education (accessed 23 June 2015).

(13) Deslauriers, L.; Schelew, E.; Wieman, C. Improved learning in a large-enrollment physics class. Science 2011, 332, 862-864.

(14) Bruff, D. The Flipped Classroom FAQ CIRTL Network, posted September 2012, http://www.cirtl.net/node/7788 (accessed 24 June 2015).

(15) Zappe, S.; Leicht, R.; Messner, J.; Litzinger, T.; Lee, H. W. 'Flipping' the classroom to explore active learning in a large undergraduate course. Proc., Am. Soc. Eng. Educ. Annu. Conf. Exhib., 2009.

(16) Gilboy, M.; Heinerichs, S.; Pazzaglia, G. Enhancing student engagement using the flipped classroom. J. Nutr. Educ. Behav. 2015, 47 (1), 109-114.

(17) Lage, M.; Platt, G.; Treglia, M. Inverting the classroom: A gateway to creating an inclusive learning environment. J. Econ. Educ. 2000, 31 (1), 30-43.

(18) Tucker, B. The flipped classroom. Educ. Next 2012, http:// educationnext.org/the-flipped-classroom/.

(19) EDUCAUSE. 7 Things You Should Know about Flipped Classrooms, 2012. https://net.educause.edu/ir/library/pdf/ELI7081. pdf (accessed 24 June 2015).

(20) Johnson, D.; Johnson, R.; Smith, K. Active Learning: Cooperation in the College Classroom; Interaction Bock Company: Edina, MN, 1991.

(21) Hake, R. Interactive-engagement versus traditional methods: A six-thousand-student survey of mechanics test data for introductory physics courses. Am. J. Phys. 1998, 66, 64-74.

(22) Bullard, L.; Felder, R.; Raubenheimer, D. Effects of Active Learning on Student Performance and Retention. 2008 ASEE Annual Conference Proceedings, ASEE, June 2008. http://www4.ncsu.edu/ unity/lockers/users/f/felder/public/Papers / ASEE08\%28ActiveLearning\%29.pdf (accessed 15 Sep 2015).

(23) Farrell, J. J.; Moog, R. S.; Spencer, J. N. A guided inquiry general chemistry course. J. Chem. Educ. 1999, 76 (4), 570-574.

(24) Lewis, S.; Lewis, J. Department from lectures: An evaluation of a peer-led guided inquiry alternative. J. Chem. Educ. 2005, 82 (1), 135139.

(25) Neville, A. Problem-based learning and medical education forty years on. Med. Prin. Prac. 2009, 18 (1), 1-9.

(26) Herreid, C. Start with a story: The case study method of teaching college science; NSTA Press: 2007.

(27) Akinoglu, O.; Tandogan, R. The effects of problem-based active learning in science education on students' academic achievement, attitude and concept learning. Eurasia J. Math., Sci., Technol. Educ. 2007, 3 (1), 71-81.

(28) Gosser, D.; Roth, V. The Workshop Chemistry Project: Peer-led team learning. J. Chem. Educ. 1998, 75 (2), 185-187.

(29) Anderson, L. W., Krathwohl, D. R, et al., Eds. A Taxonomy for Learning, Teaching, and Assessing: A Revision of Bloom's Taxonomy of Educational Objectives; Allyn \& Bacon: Boston, MA, 2001.

(30) National Research Council. How People Learn: Brain, Mind, Experience, and School; National Academy Press: Washington, DC, 2000.

(31) Hattie, J. Visible learning: A synthesis of over 800 meta-analyses relating to achievement; Routledge: New York, 2008.

(32) Cole, R.; Todd, J. Effects of web-based multimedia homework with immediate rich feedback on student learning in general chemistry. J. Chem. Educ. 2003, 80 (11), 1338-1343.

(33) Stull, J.; Varnum, S.; Ducette, J.; Schiller, J.; Bernacki, M. The many faces of formative assessment. Int. J. Teach. Learn. Higher Educ. 2011, 23 (1), 30-39.

(34) Caldwell, J. Clickers in the large classroom: Current research and best-practice tips. CBE - Life Sci. Educ. 2007, 6 (1), 9-20.

(35) Richards-Babb, M.; Drelick, J.; Henry, Z.; Robertson-Honecker, J. Online homework, help or hindrance? What students think and how they perform. J. Coll. Sci. Teach. 2011, 40 (4), 81-93.

(36) Holme, T.; Murphy, K. Assessing conceptual and algorithmic knowledge in general chemistry with ACS exams. J. Chem. Educ. 2011, 88 (9), 1217-1222.
(37) Weaver, G.; Sturtevant, H. Design, implementation, and evaluation of a flipped format general chemistry course. J. Chem. Educ. 2015, 92 (9), 1437-1448.

(38) ACT-SAT Concordance. http://www.ncsu.edu/park scholarships/pdf/act.pdf (accessed 21 Sep 2015).

(39) Glynn, S.; Brickman, P.; Armstrong, N.; Taasoobshirazi, G. Science Motivation Questionnaire II: Validation with science majors and nonscience majors. J. Res. Sci. Teach. 2011, 48 (10), 1159-1176.

(40) IBM Corp. IBM SPSS Statistics for Windows, Version 20; IBM Corp.: Armonk, NY, 2011.

(41) Cohen, J. Statistical power analysis for the behavioral sciences; Routledge: 1977.

(42) Medina, J. Brain rules: 12 principles for surviving and thriving at work, home, and school; Pear Press: Seattle, WA, 2008.

(43) DeBacker, T.; Nelson, R. Motivation to learn science: Differences related to gender, class type, and ability. J. Educ. Res. 2000, 93 (4), 245-255.

(44) Seery, M. Student engagement with flipped chemistry lectures. 2014 Spring ConfChem, 2014; http://confchem.ccce.divched.org/ 2014SpringConfChemP1 (accessed 30 Sep 2015).

(45) Hartman, J.; Dahm, D.; Nelson, E. Support for experiments in flipping: Timesaving resources aligned with cognitive science. 2014 Spring ConfChem, 2014; http://confchem.ccce.divched.org/ 2014SpringConfChemP2 (accessed 30 Sep 2015). 